\title{
Perspektif Rusia tentang Hubungan Internasional Pasca Perang Dingin
}

\author{
Umar Suryadi Bakry \\ Prodi Hubungan Internasional, Universitas Jayabaya \\ Email: u_bakry@yahoo.com.sg
}

\begin{abstract}
Abstrak
Setelah Soviet bubar dan rezim Marxis runtuh, banyak gagasan alternatif muncul di tengah komunitas akademik di Rusia, termasuk ide-ide alternatif dalam bidang Hubungan Internasional (HI). Sejumlah sarjana HI Rusia berusaha untuk merekonstruksi teori-teori HI, bukan hanya teori HI yang berkembang di Rusia selama era Marxisme, tetapi juga terhadap teori-teori HI Barat. Meskipun aspirasi pasca-Perang Dingin untuk menciptakan sebuah aliran pemikiran nasional yang berbeda tentang Hubungan Internasional di Rusia, namun upaya-upaya ini tidak bebas dari ideologi dan tujuan politik yang mengarahkan dan membimbing kebijakan luar negeri Rusia. Bahkan, sarjana HI Rusia telah berbagi dengan pemerintah Rusia dalam hal membangun teori-teori HI dengan karakteristik Rusia, terutama dalam menantang hegemoni Barat dalam ilmu sosial dan hubungan internasional. Artikel ini mencoba untuk menguraikan tiga tradisi intelektual tentang hubungan internasional yang berkembang di Rusia, yaitu Westernisme, Statisme, dan Civilizationism. Pra sarjana HI Westernizer adalah mereka yang sangat dipengaruhi oleh liberalisme Barat, statisme lebih terinspirasi oleh realisme, sementara Civilizationism lebih merupakan hibrida antara konstruktivisme dan esensialisme Rusia.
\end{abstract}

Kata kunci: perspektif Rusia, hubungan internasional, westernists, statists, civilizationist.

\begin{abstract}
After the Soviet break-up and the Marxist regime collapsed, many of alternative notions emerged in the academic community in Russia, including alternative ideas in the field of International Relations (IR). A number of Russian IR scholars attempted to reconstruct the theories of IR, not just the IR theories that developed in Russia during the era of Marxism, but also against Western IR theories. Although the post-Cold War aspirations to create a distinct national school of International Relations in Russia, but these efforts are not free from the ideology and political goal that directing and guiding Russian foreign policy. Even, IR scholars in Russia have come to shared with the Russian government in terms of building the IR theories with the Russian characteristics, especially in challenging Western hegemony in the social sciences and international relations. This article tries to elaborate three intellectual traditions of international relations that developed in Russia, namely Westernism, Statism, and Civilizationism. Westernizer IR heavily influenced by Western liberalism, Statism more inspired by the realism, while Civilizationism is more of a hybrid between the constructivism and Russian essentialism.
\end{abstract}

Keywords: Russian perspectives, international relations, westernists, statists, civilizationist.

\section{PENDAHULUAN}

\section{Sebelum era Perang Dingin (Cold}

War) berakhir, studi Hubungan Internasional

(HI) identik dengan studi HI mazhab Amerika atau dihegemoni oleh pemikiran Amerika. Sebagaimana dikatakan Stanley Hoffmann bahwa studi HI merupakan ilmu sosial Amerika (International Relations is an
American social science). ${ }^{1}$ Sebelum itu Alfred Grosser sejak 1956 secara lebih provokatif bahkan sudah menyatakan bahwa studi HI telah menjadi spesialitas (keahlian) orang Amerika (the study of International Relations was an American specialty). Ole Waever juga pernah mengatakan bahwa studi HI "is not

\footnotetext{
${ }^{1}$ Stanley Hoffmann, "An American Social Science: International Relations", dalam Daedalus, Vol. 106 No. 3 (1977), pp. 41-60.
} 
international discipline", melainkan produk dari hegemoni Amerika. Ia memprediksikan bahwa hegemoni Amerika dalam disiplin akademis HI masih akan terus berlanjut di masa depan sepanjang negara itu masih memegang hegemoni dalam hubungan internasional. $^{2}$

Setelah era Perang Dingin berakhir, ternyata banyak sarjana HI yang mulai menaruh perhatian terhadap pemikiranpemikiran mengenai HI yang berkembang di luar Amerika, bahkan di luar Barat (International Relations beyond the West). Sebagai contoh, Arlene Tickner banyak menggali pemikiran tentang $\mathrm{HI}$ di Amerika Latin, Amitav Acharya melakukan eksplorasi mengenai "teori-teori" HI versi Asia, Guy Martin dan Michael Anda berusaha melacak pemikiran-pemikiran HI khas Afrika, Qin Yaqing dan Zhao Tingyang mencoba mempromosikan studi HI madzab China, Stefano Guzzini yang mengelaborasi studi HI Eropa Timur, dan masih banyak lagi. Selain itu banyak pula perhatian diberikan untuk mengungkap pemikiran-pemikiran $\mathrm{HI}$ di sejumlah negara besar yang memiliki peran penting dalam politik dunia. Salah satu perspektif HI dari negara besar yang mulai menghiasi banyak literatur HI pasca Perang Dingin adalah pemikiran HI Rusia.

\footnotetext{
2 Ole Waever, "The Sociology of a Not So International Discipline: American and European Developments in International Relations", dalam International Organization, Vol 52 No. 4 (1998), pp. 687-727.
}

Tulisan ini berusaha mengelaborasi bagaimana perspektif Rusia tentang hubungan internasional, khususnya setelah era Perang Dingin. Seperti diketahui, masyarakat Rusia telah berubah secara dramatis sejak disintegrasi Uni Soviet menyusul berakhirnya Perang Dingin. Sejarah dunia mencatat, setiap berlangsung perubahan sosial dalam suatu masyarakat biasanya dibarengi dengan terjadinya perubahan-perubahan pemikiran. Sebab itu, dengan bubarnya Uni Soviet dan berakhirnya Perang Dingin diduga banyak sarjana sosial di Rusia membuat kemajuan intelektual dalam menyesuaikan diri dengan realitas baru. Kajian ini ingin mengetahui apakah perubahan sosial yang terjadi di Rusia diikuti dengan munculnya teori-teori atau perspektif baru dari para sarjana HI Rusia tentang politik dunia. Bagaimana Rusia baru melihat dan memposisikan dirinya di dunia, bagaimana cara Rusia melihat lingkungan internasional yang baru, dan bagaimana pengaruh warisan Soviet (Soviet legacy) terhadap diskusi mengenai hubungan internasional di Rusia, akan diulas dalam tulisan ini.

\section{MENUJU TEORI HI KHAS RUSIA?}

Karl Mannheim dan Max Weber ${ }^{3}$ mengatakan bahwa tradisi pengetahuan yang berkembang dalam suatu masyarakat berakar

\footnotetext{
${ }^{3}$ Karl Mannheim terkenal dengan teori sosiologi pengetahuan (sociology of knowledge) dan sosiologi kebudayaan (sociology of culture), sedangkan Max Weber dalam berbagai karyanya menekankan pentingnya pengaruh kebudayaan pada berbagai hal (termasuk dalam pemikiran/ilmu pengetahuan).
} 
pada kondisi sosial tertentu dan mencerminkan setting budaya masyarakat tersebut. Khusus mengenai Rusia, Mariya Omelicheva juga menegaskan bahwa ilmu sosial yang berkembang di Rusia tidak bebas dari ideologi dan tujuan politik yang mengarahkan atau memandu politik luar negeri Rusia. ${ }^{4}$ Dengan kata lain pemikiran mengenai hubungan internasional yang berkembang di Rusia dari waktu ke waktu tidak terlepas dari rezim yang berkuasa di Moskow.

Seperti diketahui, selama era Perang Dingin, perkembangan ilmu pengetahuan di Rusia (termasuk perkembangan studi HI) terbelenggu oleh pemikiran Marxis, karena memang kondisi sosial dan setting budaya masyarakat Rusia saat itu dihegemoni oleh rezim Marxisme-Leninisme. Pemikiran tentang HI di Rusia saat itu tidak berkembang layaknya pertumbuhan studi HI di berbagai negara (khususnya di Eropa Barat dan Amerika Serikat), sebab kala itu para pemimpin dan ilmuwan Rusia menganggap studi HI sebagai bidang kajian yang mencerminkan bias politik, ideologi, dan epistemologis Barat. ${ }^{5}$ Banyak sarjana Rusia memandang studi HI sebagai bidang kajian kaum imperialis. Dengan kata

\footnotetext{
${ }^{4}$ Mariya Omelicheva sebagaimana dikutip George Diepenbrock, "Ideology, Politics Thwart Creation of Russian School of International Relations", dalam http://news.ku.edu/2016/09/14/ideologypolitics-thwart-creation-russian-schoolinternational-relations [Diakses 7 Januari 2017].

5 Lihat Robert M.A. Crawford dan Darryl S.L. Jarvis (ed.), International Relations -Still an American Social Science: Toward Diversity in International Thought (New York: State University of New York Press, 2001).
}

lain, mempelajari studi HI tidak ada bedanya dengan mempelajari pemikiran imperialis.

Pasca Perang Dingin berakhir, HI menjadi wacana nyata (visible discourse) di Rusia, terutama untuk menjelaskan posisi Rusia dalam politik dunia kontemporer dan menyediakan cara atau pemikiran untuk membangun kembali Rusia sebagai kekuatan besar dalam masalah-masalah dunia. Kebutuhan akan dua hal ini memunculkan berbagai aliran pemikiran (school of thought) yang memperdebatkan arah politik luar negeri yang paling tepat bagi Rusia setelah Perang Dingin berakhir. Namun, kebutuhan akan orientasi baru dalam komunitas HI Rusia ini pun, menurut Mariya Omelicheva, tidak terlepas dari rezim yag berlaku di Moskow. Secara langsung atau tidak, ada 'internvensi' atau paling tidak 'pengaruh' dari rezim Putin terhadap pemikiran tentang $\mathrm{HI}$ yang berkembang di Rusia saat ini.

Menurut William Jackson, dalam pandangan para teoritisi HI Barat, Rusia merupakan sebuah bangsa normal (normal country). Dalam arti bahwa semua perilaku Rusia dalam hubungan internasional, baik semasa atau setelah Perang Dingin, dapat dijelaskan dan diprediksikan melalui berbagai paradigma teoritis yang mendominasi narasi tentang hubungan internasional, seperti realisme (neo-realisme), liberalisme (neoliberalisme), maupun teori sistem global. $^{6}$

\footnotetext{
${ }^{6}$ William D. Jackson, "Imaging Russia in Western International Relations Theory", dalam
} 
Dengan konteks ini, hadirnya sebuah teori HI yang khas Rusia bukan sebuah kebutuhan yang mendesak. Namun, dalam pandangan Omilicheva, banyak kecenderungan perlu mempertimbangkan keunikan (uniqueness) posisi Rusia di dunia. Sebab itu tuntan akan adanya teori HI khas Rusia didasarkan atas kebutuhab untuk menjelaskan kekhususan (specificity) dari posisi, situasi dan perliaku Rusia dalam hubungan internasional.

Menurut Omelicheva, para sarjana HI di Rusia telah berbagi (have come to share) dengan pemerintah Rusia dalam hal melahirkan pemikiran HI yang khas Rusia, khususnya dalam menggugat hegemoni Barat dalam ilmu sosial dan hubungan internasional. Dalam konteks ini, pemikiran-pemikiran yang dikembangkan oleh para sarjana HI di Rusia lebih difokuskan pada topik-topik tentang Rusia sebagai negara besar, perlawanan terhadap dominasi AS, serta tatanan dunia yang adil dan terbuka. Pemerintah Rusia telah "meminjam" atau memanfaatkan gagasangagasan ini untuk menjustifikasi politik luar negerinya pasca Perang Dingin berakhir. Bagi orang Amerika, praktik penulisan teori untuk mendukung kebijakan luar negeri mungkin aneh, tetapi tidak bagi para sarjana Rusia. Di Rusia, hampir setiap ilmu sosial (termasuk

http://www.miamioh.edu/cas/files/documents/havig hurst/2001/2001-jackson.pdf [Diakses 7 Januari 2017]. studi HI) adalah sangat ideologis (highly ideologized). ${ }^{7}$

Sebagaimana diketahui, setelah Perang Dingin bubar dan rezim Marxis runtuh, mulai tumbuh banyak pemikiran alternatif dalam komunitas akademik di Rusia, termasuk pemikiran-pemikiran alternatif di bidang hubungan internasional. Muncul sejumlah sarjana yang mulai melakukan rekonstruksi terhadap pemikiran-pemikiran tentang $\mathrm{HI}$, tidak saja terhadap pemikiran HI yang berkembang di Rusia selama era Marxisme, namun juga terhadap pemikiran HI Barat. Memang hingga saat ini belum ada kesepakatan di antara para sarjana HI Rusia mengenai karakteristik yang membedakan pemikiran HI Rusia dengan HI Barat. Tetapi setidaknya sudah ada beberapa upaya yang mereka lakukan untuk membangun teori $\mathrm{HI}$ khas Rusia yang berbeda dengan teori $\mathrm{HI}$ Barat.

Telah banyak diketahui bahwa klasifikasi yang diterapkan dalam teori-teori $\mathrm{HI}$ Barat (seperti realisme, liberalisme, teori kritis atau konstruktivisme), dibentuk oleh preferensi ideologis dari para teoritisinya. ${ }^{8}$ Realisme, misalnya, menekankan pada konsep balance of power, liberalisme pada institusi internasional, dan teori kritis atau konstruktivisme pada

\footnotetext{
${ }^{7}$ Mariya Omelicheva sebagaimana dikutip George Diepenbrock, loc. cit.

8 Andrei P. Tsygankov dan Pavel A. Tsygankov, "National Ideology and IR Theory: Three Incarnations of 'the Russian Idea'", dalam European Journal of International Relations, Vol. 16 No. 04 (2010), hal. 663-686.
} 
aspek eksploitasi dan emansipasi manusia. Sedangkan teori-teori $\mathrm{HI}$ alternatif (seperti teori HI China, teori HI India, teori HI Afrika, dan teori HI Rusia) lebih mencerminkan 'kepedulian' ideologis secara luas mengenai hubungan antara 'self' (diri kita) dengan 'other' (pihak lain).

Menurut Andrei Tsygankov dan Pavel Tsygankov, perspektif tentang hubungan internasional yang berkembang di Rusia saat ini dapat diklasifikasikan dalam tiga aliran pemikiran, yaitu Westernism, Statism, dan Civilizationism. ${ }^{9}$ Ketiga aliran pemikiran ini secara nasional bersifat sepesifik, namun pada esensinya juga memberikan eksplanasi mengenai konsep 'self' dan 'other', dan bagaimana seharusnya hubungan antara 'self' dan 'other' tersebut. Misalnya, bagaimana cara mereka mendefinisikan Rusia pasca Perang Dingin, bagaimana mereka memposisikan Rusia dalam politik dunia yang berubah, bagaimana pandangan mereka terhadap Barat (termasuk terhadap NATO dan Amerika Serikat), bagaimana mereka melihat emerging power (seperti China dan India), bagaimana mereka mendefinisikan ancaman eksternal, dan sebagainya. $^{10}$

\footnotetext{
9 Andrei P. Tsygankov dan Pavel A. Tsygankov, "Russian Theory of International Relations", dalam Robert A. Denemark (ed.), International Studies Encyclopedia (Hoboken, NJ:Wiley-Blackwell Publishers, 2010), hal. 6375-6387.

${ }^{10}$ Lihat Andrei P. Tsygankov, "Self and Other in International Relations Theory: Learning from Russian Civilizational Debates", dalam International Studies Review, Vol. 10 No. 04 (2008), hal. 762-775.
}

Ketiga tradisi intelektual atau pemikiran mengenai $\mathrm{HI}$ yang berkembang di Rusia tersebut (seperti halnya realisme, liberalisme, dan teori kritis/konstruktivisme) memberikan penakanan yang berbeda-beda mengenai hakikat 'self/other'. Westernisme mengkategorikan Rusia sebagai bagian dari Barat, Statisme menekankan pentingnya Rusia sebagai the independent state, sedangkan Civilizationisme menonjolkan konsep peradaban yang berbeda (the distinct civilization) sebagai identifikasi yang diinginkan dari pertanyaan siapa sebenarnya bangsa Rusia ('the Russian Self'). Meskipun eksistensi ketiga tradisi intelektual ini mulai terungkap setelah bubarnya Uni Soviet, namun mereka sebenarnya telah memiliki akar yang panjang dalam sejarah Rusia. Sebab itu, Tsygankov dan Tsygankov lebih melihatnya sebagai sebuah image tentang dunia yang berkembang secara sistematis dan didasarkan pada sejarah budaya lokal, dan bukan bagian dari evolusi ilmu sosial (HI) Barat. ${ }^{11}$

\section{WESTERNISME: RUSIA BAGIAN DARI BARAT}

Lalu, apa perbedaan dari ketiga aliran pemikiran tersebut? Para Westernizer memandang pemikiran Rusia pada esensinya merupakan pemikiran Barat. Mereka menekankan kesamaan (similarity) Rusia dengan negara-negara Barat dan menganggap

\footnotetext{
11 Andrei P. Tsygankov dan Pavel A. Tsygankov (2010), loc. cit.
} 
Barat sebagai peradaban yang paling baik (viable) dan paling progresif di dunia. Sejak sebelum era Perang Dingin berakhir, para Westernizer (atau di Rusia sering disebut Atlanticist) selalu berupaya memperkenalkan Rusia sebagai anggota setia dalam keluarga monarkhi Eropa. Alexander I, misalnya, memperjuangkan apa yang disebut dengan legitimist policies dan membangun "aliansi suci” dengan Jerman dan Austria guna menekan kegiatan revolusioner di dalam negeri Rusia. Di paruh kedua abad ke-19, Westernizer seperti Alexander II, mengidentifikasi dengan Barat (khususnya tentang kebebasan konstitusional dan kesetaraan politik). Para Westernizer dalam era Soviet (meskipun minoritas) juga melihat Rusia sebagai tidak terlalu jauh dari ide-ide sosial demokrasi Eropa. Misalnya, salah satu garis pemikiran Mikhael Gorbachev adalah bahwa Uni Soviet harus memurnikan diri dari distorsi Stalinis dan menjadi sebuah demokrasi atau "human version" dari sosialisme.

Pasca runtuhnya Uni Soviet, para Westernizer liberal berpendapat bahwa kedekatan alamiah negara mereka dengan Barat didasarkan pada nilai-nilai bersama (shared values) seperti demokrasi, hak azasi manusia, dan pasar bebas. Mereka bersikukuh bahwa hanya dengan membangun institusiinstitusi liberal Barat dan dengan mengintegrasikan dengan koalisi (atau yang sering disebut sebagai komunitas) "bangsabangsa beradab Barat", Rusia dapat merespon berbagai ancaman serta mengatasi keterbelakangan ekonomi dan politik. Tokoh Rusia yang dikenal mewakili kelompok Westernist diantaranya Andrei Kozyrev dan Boris Yeltsin. Mantan Perdana Menteri Rusia, Andrei Kozyrev, pernah mengatakan: "tidak diragukan Rusia tidak akan berhenti untuk menjadi kekuatan besar. Tapi Rusia akan menjadi kekuatan besar yang normal. Kepentingan nasional juga akan menjadi prioritas. Tapi kepentingan itu harus dapat dimengerti oleh negara-negara demokratis, dan Rusia akan mempertahankan kepentingan itu melalui interaksi dengan mitra (negara-negara Barat), bukan melalui konfrontasi". ${ }^{12}$

Menurut John O'Loughlin, Gearoid Ó Tuathail dan Vladimir Kolossov, para Westernizer meyakini bahwa kepentingan strategis dan geopolitik tidak berbeda secara signifikan dengan Barat. Ancaman terpenting bagi keamanan nasional Rusia bukanlah Barat, melainkan keterbelakangan ekonomi Rusia sendiri. Mereka merekomendasikan modernisasi ekonomi dan sosial didasarkan pada penyatuan dengan komunitas Barat yang didukung oleh investasi dari Barat, dan mengimpor teknologi Barat merupakan prioritas utama untuk mengatasi keterbelakangan. ${ }^{13}$ Pada skala global, mereka memandang bahwa inti dari konflik mengenai

\footnotetext{
12 Andrei Kozyrev, "Russia: A Change for Survival", dalam Foreign Affairs, Vol. 71 No. 2 (1992), hal. 10-15.

13 John O’Loughlin, Gearoid O. Tuathail, dan Vladimir Kolossov, "Russian Geopolitical Culture in the Post-9/11 Era", dalam http://www.colorado.edu/ibs/intdev/johno/pub/nazi _data/Proteus.html [Diakses 7 Januari 2017].
} 
modernitas adalah pertentangan antara negaranegara demokratis dan otoritarian. Dalam hubungannya dengan CIS $^{14}$, tugas utama Rusia adalah mendukung kebebasan ekonomi dan politik sambil menghindari setiap perselisihan perbatasan.

Dalam politik Rusia kontemporer, Westernisme biasanya dikaitkan dengan SPS (Soyuz Pravykh Sil), sebuah gerakan politik berhaluan kanan yang mencapai puncak kejayaannya pada dekade 1990-an saat awal bubarnya Uni Soviet. Bagi kelompok ini, modernisasi adalah westernisasi. Demokrasi liberal merupakan satu-satunya cara yang paling memungkinkan untuk mengatur masyarakat dan untuk mengatasi tantangan Rusia kontemporer. Sebab itu, menurut para pendukung SPS, Rusia harus mengintegrasikan dirinya ke tengah jantung pengambilan keputusan tentang modernisasi dan globalisasi (yaitu Barat). ${ }^{15}$

Dalam ranah akademis, kebanyakan sarjana HI yang beraliran Westernis identik dengan penganut liberalisme. Menurut Tsygankov dan Tsygankov, teori HI liberal yang berkembang di Rusia jauh lebih banyak

14 CIS (Commonwealth of Independent States) adalah organisasi regional yang dibentuk untuk mengelola kerjasama Rusia dengan negara-negara bekas pecahan Uni Soviet.

15 Vladimir I. Pantin, "Problems of contemporary international politics in the programs of leading political parties and movements of Russia”, dalam Social and Political Forces of Russia and the West and Problems of Globalization (Moscow: Institute of World Economy and International Relations of the Russian Academy of Sciences, 2002), hal. 139148 . dibentuk oleh pendekatan-pendekatan Barat daripada pendekatan-pendekatan Rusia lainnya. Meskipun ada perbedaan dan ketidaksepakatan di dalam liberalisme Rusia, mereka yang mendukung teori-teori liberal Barat menikmati posisi yang sangat dominan tersebut. Salah satu konsep liberalisme yang dikembangkan sarjana HI beraliran liberal di Rusia adalah "unipolaritas demokratis". Konsep ini jelas terinspirasi oleh pemikiran liberal Barat, karena demokrasi merupakan fenomena universal yang berpusat di Barat (Western-centered). Argumen dari konsep ini menunjukkan bahwa Rusia perlu mengadopsi demokrasi pluralistik Barat jika ingin menjadi negara yang damai dan "beradab", bahkan jika itu berarti harus memberikan hak istimewa kepada Amerika Serikat untuk menggunakan kekuatan (the right to use force) sebagai satusatunya negara super power yang ada di dunia.

Sementara itu arjana HI liberal lainnya, Vladimir Kolossov dan Nikolai Mironenko, mencoba memperkenalkan konsep "geopolitik kerjasama" (geopolitics of cooperation) di Eurasia. Mereka menyatakan bahwa Rusia harus bertindak sebagai pusat utama di Eurasia, bukan sebagai super power militer atau hegemon politik, tetapi kebuh sebagai mediator dalam aktivitas-aktivitas ekonomi. Kolossov meyakini bahwa geopolitik Rusia harus dibangun berdasarkan dinamika globalisasi seperti perdagangan internasional, serta arus finansial dan informasi. Namun pada saat yang sama ia juga menggarisbawahi pentingnya beberapa faktor lainnya seperti 
etnisitas, agama, sastra, musik dan seni dalam konstruksi geopolitik Rusia. ${ }^{16}$

\section{STATISME: RUSIA SEBAGAI EURASIA}

Perspektif HI kedua yang berkembang di Rusia adalah Statism. Aliran pemikiran ini memandang Rusia sebagai sebuah negara independen yang kuat (strong independent state) dan menekankan kemampuan negara untuk mengatur dan melestarikan tatanan sosial politik. Mereka juga menunjukkan kekhawatirannya terhadap pihak lain (the other) dan memperkenalkan gagasan mengenai ancaman eksternal sebagai fokus keamanan Rusia. Ancaman eksternal itu bisa datang dari arah Barat maupun Timur, tergantung situasi. Belajar dari pengalaman selama dua abad ditaklukkan bangsa Mongol dan kekalahan dalam perang melawan Jepang, Rusia telah mengembangkan kompleks psikologis mengenai rasa tidak aman (psychological complex of insecurity) dan kesiagaan untuk mengorbankan segalanya demi kemerdekaan dan kedaulatan negara. Sebagai contoh, ketika menjustifikasi kebutuhan untuk mempercepat industrialisasi, program ini dibingkai argumen dalam kerangka menanggapi ancaman eksternal yang kuat, baik dari Barat maupun Timur. ${ }^{17}$

\footnotetext{
${ }^{16}$ Emre Ersen, "The Rise of Geopolitics in Russia in the Post-Cold War Period", dalam Turkish Review of Eurasian Studies, Vol 5 No. 2 (2005), hal. 27-61.

17 Lihat Andrei P. Tsygankov dan Pavel A. Tsygankov, "National Ideology and IR Theory: Three Incarnations of "the Russian Idea", dalam
}

Menurut Tsygankov, Statisme tidak inherent sebagai aliran yang anti-Barat. Mereka hanya mencari pengakuan dari Barat dengan memberi penekanan pada kapabilitas ekonomi dan militer Rusia. Sebagai bukti bahwa Statisme tidak identik dengan pemikiran anti-Barat, misalnya dalam politik luar negeri beberapa sarjana beraliran Statis menganjurkan 'akomodasi relatif' (relative accommodation) dengan Barat, sementara beberapa sarjana lain menyukai istilah 'strategi keseimbangan' (balancing strategy). Maxim Litvinov, misalnya, mendukung sistem 'keamanan kolektif' (collective security) di Eropa untuk mencegah bangkitnya fasisme seperti di era Hitler dan Mussolini. Jadi, tesis utama dari kaum Statis adalah kebangkitan Rusia sebagai negara besar. Pada era Rusia Baru, Yevgeny Primakov dan Vladimir Putin memandang kebesaran dan kekuatan Rusia sebagai tujuan utama (key goals) dari politik luar negeri negara mereka. Selain itu agenda berikutnya yang dipandang penting oleh kaum Statis adalah mengintegrasikan kembali (reintegrate) bekas wilayah Uni Soviet dan "membendung" Amerika Serikat melalui aliansi strategis (strategic alliance) dengan China dan India. ${ }^{18}$

Emre Ersen menyebut penganut Statisme sebagai Neo-Eurasianists. ${ }^{19}$ Aliran pemikiran ini mewakili aspirasi dari mereka yang mengharapkan Rusia kembali menjadi kekuatan dominan di Eurasia (Russia as

European Journal of International Relations, Vol. 16 No. 04 (2010), hal. 663-686.

18 Ibid.

${ }^{19}$ Emre Ersen, loc. cit. 
Eurasia). Penganut aliran Neo-Eurasianist lebih memberikan penekanan pada faktorfaktor geopolitik yang memisahkan Rusia dari Barat. Mereka lebih memilih pemikir-pemikir geopolitik tradisional seperti Mackinder dan Haushofer sebagai mentor daripada pemikir Eurasianis klasik semacam Petr Savitsky dan Nicholas Trubetzkoy. ${ }^{20}$ Penganut aliran neoEurasinist dapat dikelompokkan ke dalam Neo-Eurasianist kanan baru dan NeoEurasianist sayap kiri. Mereka yang tergabung dalam Neo-Eurasianist kanan baru adalah para ilmuwan dan politisi garis keras seperti Alexander Prokhanov, Shamil Sultanov, dan Alexander Dugin. Sedangkan Neo-Eurasianist sayap kiri atau sering disebut "Eurasian Communism" diantaranya diwakili oleh Gennady Zyuganov (pemimpin Partai Komunis Rusia).

Dalam teori HI Barat pemikiran kaum Statis atau Neo-Eurasianis dapat dikatakan sebagai mewakili aliran realis. Karena termasuk dalam realisme, kepedulian utama para sarjana $\mathrm{HI}$ aliran Statis atau NeoEurasianis adalah pada perlindungan stabilitas dan keamanan negara dari ancaman luar. Salah satu contohnya adalah Aleksei Bogaturov yang memandang sistem internasional pasca Perang Dingin sebagai sebuah "unipolaritas pluralistik", dimana pusat unipolar adalah sekelompok negara-negara yang bertanggung jawab (a group of responsible states), dan

\footnotetext{
${ }^{20}$ Lihat Charles Clover, "Dream of the Eurasia Heartland", dalam Foreign Affairs, Vol. 78 No. 2 (1999), hal. 9-13.
}

bukan di tangan Amerika Serikat saja. Bogaturov melihat Rusia sebagai anggota dari kelompok negara-negara tersebut dan berpendapat bagi perlunya konsolidasi dari posisi Rusia dalam pusat global, serta untuk mematahkan semangat pembentukan unipolaritas satu negara di dunia. Pendekatan Bogaturov terhadap tatanan dunia tidak berbeda jauh dengan tradisi English School, yakni menonjolkan pentingnya aturan dan norma dalam masyarakat internasional. Ia berharap Rusia tetap mengembangkan hubungan dengan Barat, sambil menolak kecenderungan AS untuk menjadi kekuatan dominan dalam sistem internasional. ${ }^{21}$

Kaum Statis atau realis juga mengritik gagasan liberal tentang demokrasi universal yang mempertanyakan signifikansi dari karakteristik internal dalam perjuangan internasional untuk power dan keamanan. Kaum Statis/realis juga telah mengritik gagasan liberal tentang ide-ide demokrasi universal yang mempertanyakan signifikansi dari karakteristik internal dalam perjuangan internasional untuk kekuasaan dan keamanan. Banyak orang di Rusia melihat upaya untuk mempromosikan demokrasi ala Barat secara global sebagai tidak lebih dari ideologi menyelimuti perjuangan untuk mendapatkan dominasi di dunia. ${ }^{22}$ Daripada merekomendasikan pengembangan demokrasi

\footnotetext{
21 Aleksei Bogaturov sebagaimana dikutip Andrei Tsygankov dan Pavel Tsygankov, dalam Robert A. Denemark (ed.), loc. cit.

${ }^{22}$ Andrei Volodin sebagaimana Andrei Tsygankov dan Pavel Tsygankov, ibid.
} 
semacam itu, kaum Statis/realis mengusulkan bahwa Rusia sebaiknya lebih berkonsentrasi pada penguatan posisi internasional dengan mengkonsolidasikan hubungan regional dan mengejar hubungan yang tidak berat sebelah (even-handed relations) dengan negara-negara Barat dan non-Barat.

Mendukung Rusia sebagai pusat kekuatan yang secara relatif independen, kaum Statis atau realis juga mempromosikan gagasan politik luar negeri banyak arah (multi-vector foreign policy). Seorang akademisi senior dan mantan Menteri Luar Negeri Rusia, Yevgeny Primakov, mengatakan bahwa jika Rusia mempertahankan sebagai negara berdaulat dengan kemampuan untuk mengatur dan mengamankan ruang pasca-Soviet dan menolak ambisi-ambisi hegemonik di mana saja di dunia, ada alternatif untuk bertindak dalam segala arah geopolitik. Primakov dan para pengikutnya dengan tegas menolak keberpihakan Rusia terhadap Eropa atau Amerika Serikat dengan mengorbankan hubungan dengan partisipan internasional utama lainnya, seperti China, India, dan dunia Islam.

Pemikiran-pemikiran kaum Statis secara resmi telah diadopsi menjadi kebijakan politik luar negeri Rusia. Konsep Keamanan Nasional 1997, misalnya, mengidentifikasi Rusia sebagai "influential European dan Asian power". Konsep ini merekomendasikan bahwa Rusia memelihara jarak yang sama (equal distance) dalam hubungan dengan aktor-aktor ekonomi dan politik di Asia dan Eropa. Konsep resmi politik luar negeri tahun 2000 juga menyebut Rusia sebagai kekuatan besar (great power) dengan tanggung jawab untuk menjaga keamanan di dunia, baik di tingkat global maupun regional, serta mengingatkan adanya ancaman baru dari sebuah struktur dunia yang unipolar di bawah dominasi ekonomi dan militer Amerika Serikat. ${ }^{23}$

\section{CIVILIZATIONISM: PLURALISME BUDAYA}

Selain liberalisme (Westernism, Atlanticist) dan realisme (Statism, NeoEurasianism), para sarjana HI Rusia juga telah mengembangkan perspektif yang berbeda untuk memahami fundasi budaya negara Rusia dan lingkungan regionalnya. Perspektif ini secara budaya mengkombinasikan teori-teori dari kaum konstruktivis dan esensialis (essentialists). Kalau kaum esensialis budaya telah terinspirasi oleh visi tentang Eurasia yang autarkhis dan mandiri serta imperium Ortodoks, kaum konstruktivis memberi penekanan pada sintesis budaya dan dialog lintas peradaban. Namun kedua aliran pemikiran ini sama-sama bertolak dari asumsi kekhasan peradaban (civilizational distinctiveness) Rusia yang perlu dilestarikan dan dihormati, bukannya dihilangkan atau

\footnotetext{
${ }^{23}$ Tatyana Shakleyina sebagaimana dikutip Andrei P. Tsygankov dan Pavel A. Tsygankov, dalam Robert A. Denemark (ed.), loc. cit..
} 
ditekan sebagaimana yang dianjurkan kaum liberal. $^{24}$

Tsygankov dan Tsygankov menyebut aliran pemikiran yang ketiga ini sebagai Civilizationism. Penganut aliran ini berusaha mengkonseptualisasikan hubungan 'self-other' lebih dalam konteks oposisi budaya (cultural oppositions), daripada konteks ancaman sebagaimana yang dipahami kaum Statis. Tradisi intelektual ketiga ini menempatkan Rusia dan nilai-nilai yang dimilikinya (its values) secara prinsip berbeda dari Barat. Mereka memandang Rusia memiliki kebudayaan dan peradaban sendirinya. Beberapa tokoh aliran ini bahkan menghendaki Rusia memiliki "misi" di dunia atau menyebarkan nilai-nilai Rusia di luar negeri. ${ }^{25}$ Beberapa representasi dari aliran ini juga menganjurkan komitmen yang kuat terhadap nilai-nilai Kristen Ortodoks, sedangkan beberapa Civilizationist lainnya lebih melihat Rusia sebagai sintesis dari berbagai agama (selain Kristen Ortodoks juga ada Islam, Hindu, Katolik dan agama lainnya yang juga perlu dilestarikan dan dihormati).

Pada abad ke-19, kaum Civilizationist membela gagasan Persatuan Slavia (Slavic Unity), dan ideologi mereka Pan-Slavisme mempengaruhi beberapa keputusan politik luar negeri Rusia di era Tsar. Pada era Uni Soviet,

\footnotetext{
${ }^{24}$ Andrei P. Tsygankov dan Pavel A. Tsygankov, dalam Robert A. Denemark (ed.), loc. cit. .

${ }^{25}$ Lihat Peter J.S. Duncan, Russian Messianism: Third Rome, Revolution, Communism and After (London: Routledge, 2000).
}

yang lahir dari penderitaan otokratisme dan liberalisme Eropa, kaum Civilizationist melihat Rusia sebagai bangsa yang lebih unggul daripada peradaban Barat yang telah merosot dan keropos. Beberapa orang Civilizationist di era ini menentang Barat dan bentuk yang sangat tajam dan menganjurkan sebuah revolusi dunia. Namun beberapa orang Civilizationist lainnya yang moderat menghendaki hidup berdampingan secara damai (peaceful coexistence) dan sebuah kerjasama yang terbatas (limited cooperation) dengan dunia kapitalisme. Sedangkan versi lain dari Civilizationism adalah apa yang disebut dengan Eurasianism, yang melihat Rusia sebagai suatu kesatuan organik khas yang berbeda dari budaya Eropa maupun Asia. $^{26}$

Kaum esensialis melihat sistem internasional lebih dari segi pergulatan kebudayaan yang tak bisa dipertemukan (irreconcilable struggle of cultures), atau benturan peradaban (conflict of civilizations). Namun cara mereka memandang fenomena tersebut banyak berbeda dengan yang dideskripsikan Samuel Huntington. ${ }^{27}$ Memang ada yang mirip dengan deskripsi Huntington, misalnya dalam mengidentifikasi pergulatan peradaban multipolar, namun sebagian besar

\footnotetext{
26 Mengenai Eurasianisme sebagai nasionalisme Rusia yang khas ini diantaranya lihat Marlene Laruelle (ed.), Russian Nationalism, Foreign Policy, and Identity Debates in Putin's Russia (Stuttgart: Ibidem Verlag, 2014).

27 Lihat Samuel Huntington, The Clash of Civilizations and the Remaking of World Order (New York: Simon and Shuster, 1996).
} 
kaum esensialis lebih melihat konflik geokultural yang secara esensial bersifat bipolar. Konsep Alexander Dugin tentang perang besar benua (great war of continents) merupakan salah satu contoh dari jenis pemikiran esensialis ini. Bipolaritas menurut Dugin adalah hasil dari pergumulan untuk memperjuangkan values dan power antara dua pemikiran benua yang bersaing, yaitu Eurasianist yang berorientasi darat dan Atlanticist yang mengutamakan lautan. $^{28}$ Orientasi Eurasianist dengan jelas direpresentasikan oleh Rusia, Jerman, dan Iran, sedangkan postur Atlanticist dengan baik diperankan oleh Amerika Serikat dan Inggris.

Sementara itu jika dilihat dari perspektif konstruktivis, fakta bahwa dunia secara budaya bersifat pluralis, namun ini tidak berarti bahwa kebudayaan-kebudayaan ditakdirkan untuk berkonflik. Sebaliknya, mereka harus berusaha membangun sebuah rezim "kesatuan dalam keragaman" (unity in diversity). Dalam 'rezim' seperti ini, kita (self) dan budaya lain (other) harus mampu memelihara sebuah dialog dan kerjasama yang intens dengan memperhatikan aturan-aturan tertentu yang diakui secara global, namun masih memungkinkan untuk memelihara seperangkat norma yang dikembangkan sendiri-sendiri secara internal. Dalam rangka mempertahankan sistem pluralis secara kultural, ide-ide baru baru diperlukan untuk

28 Lihat Alexander Dugin, Velikaia voina kontinentov - The Great War of the Continents (Moskow: Arktogeya, 2002). menentang dominasi Amerika Serikat yang berpusat pada globalisasi ekonomi dan politik. $^{29}$

Beberapa sarjana konstruktivis Rusia mengusulkan penguatan PBB sebagai prototype bagi pemerintahan dunia di masa depan (dengan Majelis Umum sebagai Parlemen, Dewan Keamanan sebagai badan eksekutif, dan Sekjen PBB sebagai Presiden dari 'negara dunia'. Sebagai contoh, mantan penasihat Presiden Gorbachev, Georgi Shakhnazarov, berpendapat bahwa penguatan PBB semacam ini diperlukan dalam rangka untuk mengatasi masalah-masalah global yang mendesak, seperti bangkitnya militerisme, menipisnya sumber daya dunia, kelebihan penduduk, dan degradasi lingkungan, serta untuk mengurangi dorongan-dorongan egois dari peradaban lokal. Dalam pandangan Shakhnazarov, restrukturisasi DK PBB yang diusulkan Huntington agar sesuai dengan representasi peradaban, dapat diartikan membuang semua potensi positif dari PBB. Untuk melestarikan dan mengembangkan struktur pemerintahan dunia yang sentral, ia mengusulkan pengembangan PBB secara bertahap, mulai dengan memasukkan ke dalam DK PBB negara-negara yang telah memiliki pengaruh yang tak terbantahkan di dunia seperti Jerman dan Jepang (bahkan mungkin India, Brazil, dan negara-negara lainnya).

\footnotetext{
${ }^{29}$ Andrei P. Tsygankov dan Pavel A. Tsygankov, dalam Robert A. Denemark (ed.), loc. cit. .
} 
Para sarjana esensialis dan konstruktivis juga sedikit berbeda pandangan dalam masalah politik luar negeri Rusia. Kaum esensialis bersikukuh dengan kebijakan untuk memulihkan status geopolitik Rusia mengenai daerah jantung Eurasia (Eurasian Heartland) dan sebagai imperium yang mandiri, serta menawarkan ide-ide baru yang menarik bagi dunia. Sementara para sarjana konstruktivis Rusia berpendapat bahwa dialog budaya sebagai prinsip humanistik yang utama yang dapat mengatur dunia dan memecahkan masalah-masalah global seperti militerisme, kemiskinan, dan degradasi lingkungan. Sedangkan para pemikir konservatif yang banyak terpengaruh nilai-nilai Kristen Ortodoks lebih menganjurkan sintesis lintas agama, terutama antara Barat yang rasional dan Timur yang mitos. Mereka melihat Rusia sebagai tempat alamiah bagi sintesis semacam itu, sehingga bisa menjadi model bagi dunia.

\section{KESIMPULAN}

Pasca Perang Dingin upaya untuk membangun teori $\mathrm{HI}$ alternatif tumbuh di luar Barat, termasuk di Rusia. Setelah rezim Marxis runtuh, mulai banyak pemikiran alternatif dalam komunitas akademik di Rusia, termasuk pemikiran-pemikiran alternatif di bidang hubungan internasional. Muncul sejumlah sarjana yang mulai melakukan rekonstruksi terhadap pemikiran-pemikiran tentang $\mathrm{HI}$, tidak saja terhadap pemikiran $\mathrm{HI}$ yang berkembang di Rusia selama era Marxisme, namun juga terhadap pemikiran HI Barat. Memang hingga saat ini belum ada kesepakatan di antara para sarjana HI Rusia mengenai karakteristik yang membedakan pemikiran HI Rusia dengan HI Barat. Tetapi setidaknya sudah ada beberapa upaya yang mereka lakukan untuk membangun teori $\mathrm{HI}$ khas Rusia yang berbeda teori HI Barat.

Ada sejumlah konsep baru muncul dalam wacana HI Rusia, misalnya konsep "democratic unipolarity", "multi-vector foreign policy", "geopolitics of cooperation", dan sebagainya. Kendati demikian, teori HI Rusia yang lahir setelah pecahnya Uni Soviet, secara umum belum dapat dikatakan sebagai teori yang benar-benar baru, melainkan lebih merupakan "bentuk baru" dari pembingkaian realitas. Beberapa perdebatan yang terjadi dalam wacana teori HI Rusia akhir-akhir ini bahkan lebih merupakan "pengulangan" dari perdebatan lama tentang "ide Rusia" (Russian Idea) yang telah terjadi pada abad ke-19 antara kelompok Westernizer dan Slavophile. Menurut sejumlah sarjana HI Rusia, dihidupkanya perdebatan mengenai Russian Idea ini justru merupakan salah satu upaya serius untuk menuju kearah teori HI khas Rusia (sebagai alternatif dari teori-teori HI Barat).

\section{KEPUSTAKAAN}


Clover, Charles, "Dream of the Eurasia Heartland", dalam Foreign Affairs, Vol. 78 No. 2 (1999), hal. 9-13.

Crawford, Robert M.A. dan Darryl S.L. Jarvis (ed.), International Relations -Still an American Social Science: Toward Diversity in International Thought (New York: State University of New York Press, 2001).

Dugin, Alexander, Velikaia voina kontinentov The Great War of the Continents (Moskow: Arktogeya, 2002).

Duncan, Peter J.S., Russian Messianism: Third Rome, Revolution, Communism and After (London: Routledge, 2000).

Ersen, Emre, "The Rise of Geopolitics in Russia in the Post-Cold War Period", dalam Turkish Review of Eurasian Studies, Vol 5 No. 2 (2005), hal. 2761.

Hoffmann, Stanley, "An American Social Science: International Relations", dalam Daedalus, Vol. 106 No. 3 (1977), pp. 41-60.

Huntington, Samuel, The Clash of Civilizations and the Remaking of World Order (New York: Simon and Shuster, 1996).

Jackson, William D.,"Imaging Russia in Western International Relations Theory", dalam http://www.miamioh.edu/cas/files/do cuments/havighurst/2001/2001jackson.pdf [Diakses 7 Januari 2017].

Kozyrev, Andrei, "Russia: A Change for Survival", dalam Foreign Affairs, Vol. 71 No. 2 (1992), hal. 10-15.

Lane, David dan Vsevovold Samakhvalov (ed.), The Eurasian Project and Europe: Regional Discountinuities and Geopolitics (Basingstoke: Palgrave Macmillan, 2015).
Laruelle, Marlene (ed.), Russian Nationalism, Foreign Policy, and Identity Debates in Putin's Russia (Stuttgart: Ibidem Verlag, 2014).

Marten. Kimberly, “Putin's Choices: Explaining Russian Forein Policy and Intervention in Ukraine", dalam The Washington Quarterly, Vol. 38 No. 2 (2015), hal. 189-204.

O’Loughlin, John, Gearoid O. Tuathail, dan Vladimir Kolossov, "Russian Geopolitical Culture in the Post-9/11 Era", dalam http://www.colorado.edu/ibs/intdevjohno/pub/nazi_data/Proteus.html [Diakses 7 Januari 2017].

Omelicheva, Mariya, sebagaimana dikutip George Diepenbrock, "Ideology, Politics Thwart Creation of Russian School of International Relations", dalam

http://news.ku.edu/2016/09/14/ideolo gy-politics-thwart-creation-russianschool-international-relations [Diakses 7 Januari 2017].

Pantin, Vladimir I., "Problems of contemporary international politics in the programs of leading political parties and movements of Russia”, dalam Social and Political Forces of Russia and the West and Problems of Globalization (Moscow: Institute of World Economy and International Relations of the Russian Academy of Sciences, 2002), hal. 139-148.

Pursiainen, Christer, Russian Foreign Policy and International Relations Theory (London: Routledge, 2000).

Rangsimaporn, Paradorn, Russian as an Aspiring Great Power in Asia: Perceptions and Policies from Yeltsin to Putin (Basingstoke: Palgrave Macmillan, 2009).

Ratti, Luca, "Back to the Future? International Relations Theory and NATO-Russia Relations since the end of the Cold 
War", dalam International Journal, Vol. 64 No. 2 (2009), hal. 399-422.

Selvaggio, Angie, "Ideas, Identity, and Interests: A Study of US-Russian Relations in the Post Cold War World", dalam http://www.cla.auburn.edu/alapsa/ass ets/file/1aselvaggio-pdf [Diakses 5 Januari 2017].

Tsygankov, Andrei P., "Self and Other in International Relations Theory: Learning from Russian Civilizational Debates", dalam International Studies Review, Vol. 10 No. 04 (2008), hal. 762-775.

Tsygankov, Andrei P. dan Pavel A. Tsygankov, "National Ideology and IR Theory: Three Incarnations of 'the Russian Idea", dalam European Journal of International Relations, Vol. 16 No. 04 (2010), hal. 663-686.
Tsygankov, Andrei P. dan Pavel A. Tsygankov, "Russian Theory of International Relations", dalam Robert A. Denemark (ed.), International Studies Encyclopedia (Hoboken, NJ:Wiley-Blackwell Publishers, 2010), hal. 6375-6387.

Voeten, Erik, "Putin and Obama clash over International Relations Theory", dalam The Washington Post, 29 September 2015.

Waever, Ole, "The Sociology of a Not So International Discipline: American and European Developments in International Relations", dalam International Organization, Vol. 52 No. 4 (1998), pp. 687-727.

Wieclawski, Jacek, "Contemporary Realism and the Foreign Policy of Russian Federation", dalam International Journal of Business and Social Science, Vol. 2 No. 1 (2011). 